\title{
Life Cycle Assessment Used to Determine Potential Midpoint Environment Impact Factors and Water Footprint of Field-grown Tree Production Inputs and Processes
}

\author{
Dewayne L. Ingram ${ }^{1,3}$ \\ Department of Horticulture, University of Kentucky, N-308F Agricultural Science Center, Lexington, \\ KY 40546-0091 \\ Charles R. Hall ${ }^{1,2}$ \\ Department of Horticultural Sciences, Texas A\&M University, 2133 TAMU, College Station, TX \\ 77843-2133
}

\begin{abstract}
AdDITIONAL INDEX WORDS. carbon footprint, global warming potential, ozone depletion, smog, acidification, eutrophication, carcinogenic or non-carcinogenic human toxicity, respiratory effects, ecotoxicity, fossil fuel depletion, nursery crops, Acer rubrum, Picea pungens, Cercis canadensis

ABstract. Previously published life cycle assessment (LCA) studies regarding the global warming potential (GWP) of tree production have shown that the carbon footprint during the cradle-to-grave life cycle of a tree can reduce atmospheric $\mathrm{CO}_{2}$. This study provides another unique contribution to the literature by considering other potential midpoint environmental impacts such as ozone depletion, smog, acidification, eutrophication, carcinogenic or noncarcinogenic human toxicity, respiratory effects, ecotoxicity, and fossil fuel depletion for 5-cm-caliper, field-grown, spade-dug trees. Findings from this study validate using data from various literature sources with a single-impact focus on GWP and compiled and calculated in a spreadsheet or using a LCA software package with embedded databases (SimaPro) to generate comparable GWP estimates. Therefore, it is appropriate to use SimaPro to generate midpoint environmental impact estimates in LCA studies of field-grown trees. The authors also compared the midpoint environmental impacts with other agricultural commodities [corn (Zea mays), soybean (Glycine max), potato (Solanum tuberosum), and wool] and determined that trees compare favorably, with the exception that fossil fuel depletion for the trees was greater than the other products as a result of the high equipment use in harvesting and handling trees. In addition, the water footprint (WF) associated with tree production is also determined through LCA using the Hoekstra water scarcity method in SimaPro. The propagation-to-gate WF for the three tree production systems ranged from 0.09 to $0.64 \mathrm{~m}^{3}$ per tree and was highly influenced by irrigation water, which was the major contributor to WF for each production system. As expected, the propagation stage of each tree represented significantly less WF than the field production phase with larger plants and lower planting densities, even with more frequent irrigation/misting in liner production.
\end{abstract}

Trees have significant positive environmental impacts in the landscape. Urban foresters have published significant evidence for air quality improvement, carbon sequestration, microclimate modification, storm water mitigation, and reduced requirements for heating and cooling buildings (McPherson and Simpson, 1999; Nowak et al., 2008; Peper et al., 2009). However, processes used during tree production at the farm level can negatively affect environmental impact factors. LCA has been used to determine the carbon footprint or GWP reported as kilogram $\mathrm{CO}_{2}$-equivalent $\left(\mathrm{CO}_{2} \mathrm{e}\right)$ of 5-cm-caliper, fieldgrown, spade-dug trees (Ingram, 2012, 2013; Ingram and Hall, 2013). Fortunately, when considering the entire life cycle from cradle to grave, trees represent a significant positive contribution to the environment.

Field-grown tree production results in emissions of greenhouse gases (GHG), which contribute 13.3 (adjusted to 16.5 for a consistent, more inclusive GWP of fuels), 17.1 and $17.1 \mathrm{~kg} \mathrm{CO}_{2} \mathrm{e}$

Received for publication 21 Oct. 2014. Accepted for publication 5 Dec. 2014. ${ }^{1}$ Professor.

${ }^{2}$ Ellison Chair in International Floriculture.

${ }^{3}$ Corresponding author. E-mail: dingram@uky.edu. to the GWP for Acer rubrum (red maple) (Ingram, 2012), Picea pungens (blue spruce) (Ingram, 2013), and Cercis canadensis (redbud) (Ingram and Hall, 2013), respectively, from propagation to the nursery gate. Accounting for carbon sequestration during production, the nursery-gate GWP was reported to be 0.8 (adjusted to 4.1), 8.1, and $6.6 \mathrm{~kg} \mathrm{CO}_{2} \mathrm{e}$ for red maple, blue spruce, and redbud, respectively. Carbon sequestration during a useful life in the landscape reduces atmospheric $\mathrm{CO}_{2}$ during a 100 -year assessment period, even when allowing for GHG emissions during takedown and disposal at end of life. The major contributor $(71 \%$ to $76 \%)$ to the GWP during production of field-grown trees was shown to be equipment use or diesel and gasoline consumption (Ingram, 2012, 2013; Ingram and Hall, 2013). Equipment use also contributes significantly to the variable costs of production (Hall and Ingram, 2014).

Previous LCA research on field tree production has only focused on GWP of input products and processes. GHG emissions were calculated for input products embedded in and resulting from processes used in the production system (Ingram, 2012, 2013; Ingram and Hall, 2013). However, these products and process may have other environmental impacts, including ozone depletion, smog, acidification, eutrophication, 
carcinogenic or non-carcinogenic human toxicity, respiratory effects, ecotoxicity, and fossil fuel depletion [U.S. Environmental Protection Agency (USEPA), 2008]. These are categorized as midpoint impact potentials with analyses that minimize the amount of forecasting and yield predictable environmental impact suitable for relative comparisons. Endpoint analysis requires estimating specific damage to human health or the environment (i.e., crop damage, skin cancer, cataracts, and immune system suppression) and is characterized by higher levels of uncertainty than midpoint impact potentials (Bare et al., 2003; USEPA, 2008).

Water footprint, expressed in cubic meters of water per functional unit produced, is another calculation that can be performed with the production and process data from LCA analyses. It is not a direct measure of water use or withdrawal from the ecosystem but is a term adjusted for water use or withdrawal on a country or river basin scale. Calculations based on water use instead of water withdrawal may be a more complete and accurate method of measuring WF for agriculture because $\approx 40 \%$ of withdrawals typically flow to local streams and aquifers (Perry, 2007; Shiklomanov, 2000).

Input to WF calculations includes withdrawal or consumption from surface and groundwater flows required by a product or process using a correction factor for the availability and consumption of water in a global region on a monthly basis, defined as the water scarcity indicator (WSI). The WSI also takes into consideration the water requirements for healthy ecosystems in the region in defining available "blue" water as the volume of water that can be consumed without adverse ecological impacts. Blue water is generally characterized as the consumptive use of surface and groundwater flows. "Green" water is considered the direct precipitation that does not run off or recharge the groundwater but is stored in the soil and evaporated from the surface or through the crop. For the lower midwestern region of the United States, the WSI reflects low stress when adjusted by a water use-to-availability ratio for the region (Alcamo et al., 2000; Smakthin et al., 2004). When considered on a monthly basis, there is more WSI stress during the summer months, the time that blue water is added by irrigation to augment available soil moisture. Green water is replenished on an annual basis in this region, and therefore, its use by crops has little impact on the WF. This would not necessarily be true in an arid region or country.

The leading internationally reviewed methods of calculating WF with adjustments for WSI include the Boulay et al. (2011), Hoekstra et al. (2012), and Pfister et al. (2009) methods. The Pfister method is based on a water withdrawal-to-availability ratio. The Hoekstra and Boulay methods use a consumption-toavailability ratio. Average global WF, using the Hoekstra method, for tomatoes and fresh apples were reported as 214 and $822 \mathrm{~m}^{3} \cdot \mathrm{t}^{-1}$, respectively (Mekonnen and Hoekstra, 2010b).

The purpose of the research presented here is to assess several midpoint environmental and human impact factors as well as the WF from previously published LCA analyses of tree production models focused on GWP.

\section{Materials and Methods}

The GWP of model system components for field production of red maple, blue spruce, and redbud have been published (Ingram, 2012; Ingram, 2013; Ingram and Hall, 2013) using LCA techniques following internationally approved guidelines
(British Standards Institute, 2011; International Organization for Standardization, 2006). These previous studies used a spreadsheet to accumulate inputs and calculate the GWP associated with the model tree production system components. However, databases such as the U.S. life-cycle inventory (USLCI) database (U.S. Department of Energy, 2014) and the Ecoinvent database (Ecoinvent Centre, 2014) contain documentation of a wide array of emissions to water and air other than GHG and are accessible through a LCA software package, SimaPro (PRé North America, Washington, DC).

The first step toward meeting the objective of the current research was to use SimaPro and embedded databases to determine the GWP of published tree production systems and compare the results with previously published data. Data for the red maple used in this study were updated to reflect the more inclusive values for the GWP of diesel and nitrogen fertilizer used in the blue spruce and redbud LCA analyses. If GWP of production systems previously published were similar to the SimaPro analysis, or any differences were explainable, SimaPro would be an effective tool to calculate additional environmental impact categories from those production system data. The answer to that question was affirmative and details are reported in the "Results and Discussion."

SimaPro was used to determine the precision of previously published GWP data for tree production using TRACI 2.1 calculation methods (Bare, 2011). TRACI, Tool for the Reduction and Assessment of Chemical and other environmental Impacts, is a midpoint-oriented LCA methodology developed by the USEPA, specifically for the United States, using input parameters consistent with U.S. locations with a 2008 weighting (USEPA, 2008). A Monte Carlo analysis with 1000 iterations was used and the uncertainty, as measured by SD for each tree production system analysis, was determined. SimaPro and methods described previously were used to determine the contributions for the tree production system components to other potential midpoint environmental and human impact categories.

The potential for ozone depletion of all emissions per product was expressed as kilograms chlorofluorocarbon (CFC-11) equivalents. The potential contributions to smog were expressed as $\mathrm{O}_{3}$ equivalents. Acidification potential for the system was expressed in kilograms $\mathrm{SO}_{3}$ equivalents. The potential contributions to eutrophication were expressed in kilograms nitrogen equivalents $(\mathrm{Ne})$ with the other primary contributor being phosphorus. Potential respiratory effects were expressed as kilogram of particulate matter less than $2.5 \mu \mathrm{m}$ in diameter $\left(\mathrm{PM}_{2.5}\right)$. Fossil fuel depletion is a fossil fuel calculation based on the surplus energy for future mining, expressed in $\mathrm{MJ}$ surplus (Müller-Wenk, 1998). Ecotoxicity potential is a relatively broad measure of environmental impact factors of input materials using the USEtox ${ }^{\mathrm{TM}}$ model (USEtox, 2013) and expressed in rather broad terms as comparative toxic unit equivalents (CTUe). USEtox ${ }^{\mathrm{TM}}$ was designed to describe the fate, exposure, and potential ecotoxicological and human effects of chemicals. The estimated potential increase in morbidity in the total human population per kilogram of chemical emitted is expressed as carcinogenic or non-carcinogenic impact expressed as comparative toxic unit for humans (CTUh).

To provide context for the tree production impacts, additional agricultural products were chosen from the USLCI database for analysis. TRACT 2.1 was used to calculate their impact potentials.

Water footprint is a midpoint impact measure as described for the categories described previously. As is true for other 
impact categories, the accumulation of WFs of input materials and processes in a product such as a tree plus a function of the irrigation water applied constitutes the WF of the tree at the nursery gate. The Hoekstra water scarcity method in SimaPro was used to calculate WF, specifying that the irrigation water was defined as withdrawn from a river in the United States. However, the WSI and calculated WF specifying lake or well sources using regional water availability averages were identical to the WF for river withdrawal. The Hoekstra method uses WSI based on a ratio of consumption to availability compared on a monthly basis. Availability in a region considers runoff water, of which $80 \%$ is subtracted from available water for ecosystem needs. Water availability averages for global regions were based on averages of freshwater withdrawal from country data (Gleick et al., 2011). This method uses runoff water and water consumption for major river basins globally as determined by Fekete et al. (2002) and Mekonnen and Hoekstra (2010a), respectively.

\section{Results and Discussion}

The differences between published GWP for propagationto-gate production of red maple, blue spruce, and redbud and those calculated using SimaPro were 1.78, 0.07, and $0.58 \mathrm{~kg} \mathrm{CO}_{2} \mathrm{e}$ $(10.7 \%, 0.4 \%$, and $3.4 \%)$, respectively (Table 1$)$. The SDs $(95 \%$ level) for total GWP using Monte Carlo analysis in SimaPro were $0.54,0.24$, and 0.28 for the three, respectively. In the analysis of each species, some activities and inputs were higher for the previously published data than the SimaPro estimations, whereas others were higher using SimaPro.

GWP contributions of diesel use were consistently higher in the SimaPro analysis. Diesel in Simapro used the USLCI database to include at the refinery and combustion in industrial equipment impacts to total $3.24 \mathrm{~kg} \cdot \mathrm{L}^{-1} \mathrm{CO}_{2} \mathrm{e}$, whereas previously published work used the GREET model (Vyas and Singh, 2011) for total Well-to-Wheel GWP from U.S. Transportation data
(3.02 $\mathrm{kg} \cdot \mathrm{L}^{-1} \mathrm{CO}_{2} \mathrm{e}$ ) for low-sulfur diesel. Well-to-Wheel GWP for gasoline from GREET was $2.93 \mathrm{~kg} \cdot \mathrm{L}^{-1} \mathrm{CO}_{2} \mathrm{e}$ and U.S. life cycle inventory database in SimPro calculations used a GWP of $2.60 \mathrm{~kg} \cdot \mathrm{L}^{-1} \mathrm{CO}_{2} \mathrm{e}$. This makes a modest difference given that fuels contributed $61 \%$ to $76 \%$ to production GWP. The slightly higher GWP for liner production using SimaPro was attributable primarily to the difference in diesel GWP used. The GWP of gasoline use was slightly higher in the published data but made little overall impact as a result of the relatively small gasoline use compared with diesel.

The contribution of fertilizers on GWP was greater in published data for the three trees compared with the SimaPro analysis because the impact of $\mathrm{N}_{2} \mathrm{O}$ loss directly from field-applied fertilizer equal to $1 \%$ of applied $\mathrm{N}$ was included (Snyder et al., 2009). The fertilization GWP in red maple was higher than for the other trees because the model system used ammonium nitrate as the nitrogen source instead of urea. Ammonium nitrate has more embedded energy than urea.

The model system for red maple included fiberglass stakes and the best available data in SimaPro were higher than for previously published data. Data available through SimaPro did not include the GWP for bamboo stakes. The SimaPro analysis accounted for the processes of wire manufacturing and welding the basket together, which was not included in the previously published data. This difference was $0.727 \mathrm{~kg} \mathrm{CO}_{2} \mathrm{e}$ per tree.

Data for some processes and input products used in SimaPro analyses included embedded impacts of the manufacturing or construction of capital goods, which were omitted from previous LCA analysis of the trees according to PAS 2050 (British Standards Institute, 2011). Capital goods used vary greatly among commercial nurseries in the lower midwestern United States, making it unfeasible to develop a representative model of this overhead. Therefore, overhead from capital goods manufacturing and construction was outside the model boundary of the previously published tree LCAs.

Table 1. Comparison of previously published global warming potential of the production of field-grown red maple, blue spruce, and redbud using a spreadsheet approach or using SimaPro life cycle assessment software and embedded databases (PRé North America, Washington, DC).

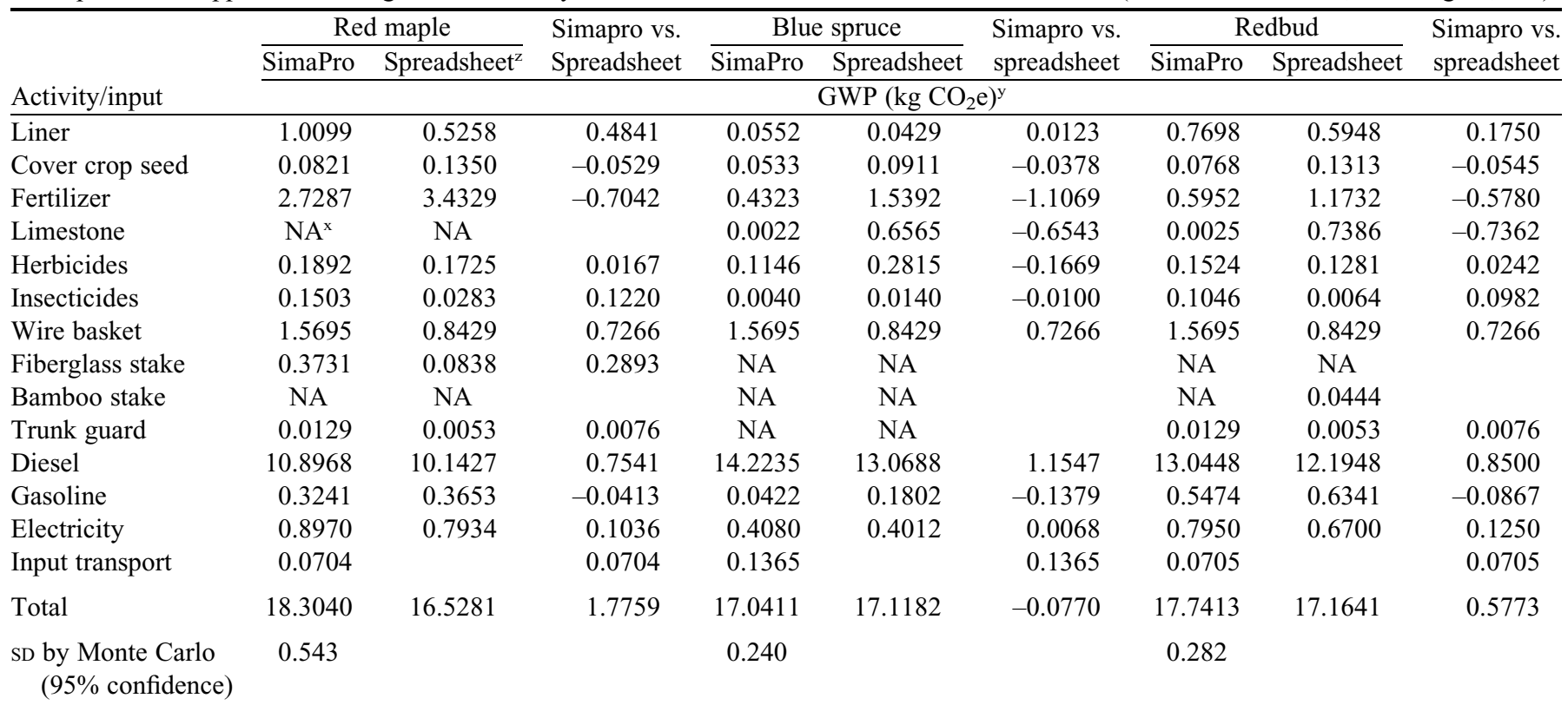

${ }^{\mathrm{z}}$ Published data from single-impact analyses with spreadsheet-based compilation and calculations (Ingram 2012, 2013; Ingram and Hall, 2013). ${ }^{\mathrm{y}}$ Carbon dioxide equivalent.

${ }^{\mathrm{x}}$ Not available. 


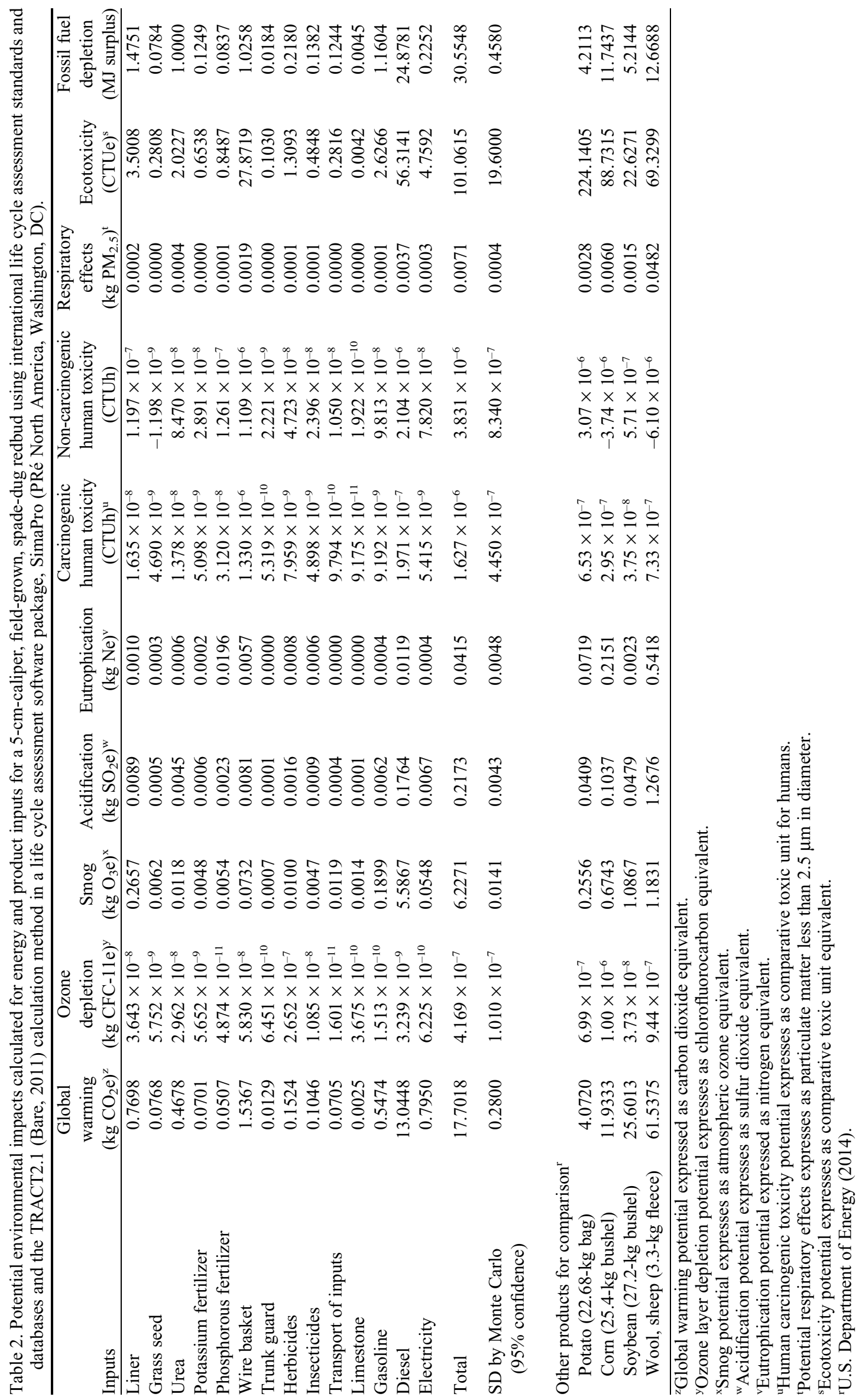


The LCA using SimaPro compared closely with previously published GWP for these three field-grown trees and were characterized by relatively low uncertainty. This analysis only included the emissions related to production (propagation-tofarm gate) and did not include emissions from transport to the landscape site and transplanting nor $\mathrm{C}$ sequestration during production. Therefore, SimaPro can confidently be used to calculate other midpoint environmental and human potential impact categories using previously published model systems for these crops.

The calculated values for the other selected midpoint impact categories paralleled the GWP data for all three trees; therefore, only the redbud data are presented here (Table 2 ). The relative impact potential of identified input products and activities in these systems requiring fuels and electricity on smog, acidification, respiratory effects, ecotoxicity, and fossil fuel depletion tracked closely with the contributions of those energy-rich activities and products to GWP of redbud production. Ozone depletion potential was calculated to be $4.17 \times 10^{-7} \mathrm{~kg}$ CRC-11-e and was most influenced by herbicide use followed by the wire basket, urea, and insecticide use. Acidification potential from redbud production totaled $0.217 \mathrm{~kg} \mathrm{SO}_{2} \mathrm{e}$ and diesel use was the primary contributor followed by the wire basket, gasoline, and urea. Total eutrophication potential was $0.042 \mathrm{~kg} \mathrm{Ne}$ and was impacted most by phosphorous fertilizer and diesel use. Human carcinogenic toxicity potential for redbud production was $1.63 \times$ $10^{-6}$ CTUh with primary contributors being the wire basket followed by diesel, the liner, and phosphorus fertilizer use. Noncarcinogenic human toxicity potential totaled $3.83 \times 10^{-6} \mathrm{CTUh}$ with the diesel, wire basket, and phosphorus fertilizer and the liner making the greatest contribution. Potential respiratory effects totaled $0.007 \mathrm{~kg} \mathrm{PM}_{2.5}$ with diesel contributing more than $50 \%$ of the impact potential. The total ecotoxicity potential of redbud production was 101.06 CTUe with the dominant contributors being diesel and the wire basket. Eighty-one percent of the potential fossil fuel depletion (30.555 MJ surplus) was from the use of diesel.

Standard deviations from the Monte Carlo estimates show that potential human carcinogenic and noncarcinogenic human toxicity, ozone depletion, and ecotoxicity are the most variable of the impact potentials calculated. This indicates that less emphasis should be placed on their absolute values per se but are best used for comparison and to establish general trends. The potential GWP, smog, acidification, eutrophication, respiratory effect, and fossil fuel depletion impacts are much less variable and lend themselves to more rigorous comparisons between products or processes.

The relevance of these potential impact numbers can be more easily understood when compared with those of other products, although the cropping cycle differs and trees provide ecosystem services after production, whereas these other agricultural products require further processing before use. Potential environmental and human impacts for other agricultural products as reported in the USLCI database and calculated using TRACT2 are presented in Table 2 . A bushel of soybeans $(27.2 \mathrm{~kg})$ or corn $(25.4 \mathrm{~kg})$, a $22.7-\mathrm{kg}$ bag of potatoes, and a fleece of wool $(3.3 \mathrm{~kg})$ at the farm gate would result in GWP of 25.6, 11.9, 4.1, and $61.5 \mathrm{~kg} \mathrm{CO}_{2} \mathrm{e}$, respectively. Eutrophication potentials were notably higher for corn and wool than the redbud tree; however, fossil fuel depletion for the tree was greater than the other products. Human carcinogenic and non-carcinogenic toxicity potentials for these agricultural products were highly variable but similar to redbud. This is the result of the high equipment use in harvesting and handling individual trees. Cambria and Pierangeli (2011) reported GWP, eutrophication expressed in terms of phosphate equivalents, ozone layer depletion, and acidification potential for the production of a 2-year-old walnut (Juglans regia) seedling as $0.229 \mathrm{~kg} \mathrm{CO}_{2} \mathrm{e}, 0.57 \mathrm{~kg} \mathrm{PO}_{4} \mathrm{e}, 4.01 \times 10^{-7} \mathrm{~kg} \mathrm{CFC}-11 \mathrm{e}$, and $0.844 \mathrm{SO}_{2} \mathrm{e}$, respectively. Compared with the redbud liner, the GWP of the walnut seedling was lower, but the other parameters studied were generally higher. Muñoz et al. (2007) reported that GWP, and potential eutrophication, ozone layer depletion, and acidification potential for a kilogram of greenhouse-grown tomatoes in the Mediterranean as $0.074 \mathrm{~kg} \mathrm{CO}_{2} \mathrm{e}, 1.23 \times 10^{-4} \mathrm{~kg} \mathrm{PO}_{4} \mathrm{e}$, $8.97 \times 10^{-9} \mathrm{~kg} \mathrm{CFC}-11 \mathrm{e}$, and $4.84 \times 10^{-4} \mathrm{SO}_{2} \mathrm{e}$, respectively.

Irrigation water applied for the modeled red maple, redbud, and blue spruce production systems, including liner production, was $0.623,0.693$, and $0.078 \mathrm{~m}^{3}$ per tree, respectively. These values are higher than the WFs that were adjusted by the WSI for the region. WF as determined by the Hoekstra method differed among the three tree production systems (Table 3). By far, irrigation water was the major contributor to WF for each production system, accounting for $76 \%$ to $97 \%$ of the WF.

Table 3. Water footprint (WF) expressed $\mathrm{as}^{3}$ for the components of 5-cm-caliper, field-grown, spade-dug tree (red maple, redbud, and blue spruce) production systems using international life cycle assessment standards, SimaPro software and embedded databases (PRé North America, Washington, DC), and the Hoekstra calculation method (Hoekstra et al., 2012).

\begin{tabular}{|c|c|c|c|}
\hline \multirow[b]{2}{*}{ Inputs } & Red maple & Redbud & Blue spruce \\
\hline & \multicolumn{3}{|c|}{--------------------------- WF $\left(\mathrm{m}^{3}\right.$ ) -------------------------- } \\
\hline Irrigation in field production & 0.5599 & 0.6251 & 0.0676 \\
\hline Liner production & 0.0018 & 0.0012 & 0.0023 \\
\hline Cover crop seed & 0.0018 & 0.0004 & 0.0003 \\
\hline Nitrogen fertilizer & 0.0018 & 0.0010 & 0.0001 \\
\hline Potassium chloride & 0.0000 & 0.0012 & 0.0007 \\
\hline Phosphorous fertilizer & 0.0000 & 0.0000 & 0.0000 \\
\hline Limestone & 0.0000 & 0.0000 & 0.0000 \\
\hline Steel, low-alloyed & 0.0154 & 0.0154 & 0.0154 \\
\hline Wire drawing, steel & 0.0017 & 0.0017 & 0.0017 \\
\hline Welding, arc, steel & 0.0001 & 0.0001 & 0.0001 \\
\hline Glass fiber stake & 0.0065 & 0.0000 & 0.0000 \\
\hline Corrugated board trunk guard & 0.0006 & 0.0006 & 0.0000 \\
\hline Herbicides & 0.0006 & 0.0008 & 0.0001 \\
\hline Glyphosate & 0.0008 & 0.0003 & 0.0007 \\
\hline Insecticides & 0.0008 & 0.0006 & 0.0000 \\
\hline Transport of input products & 0.0000 & 0.0000 & 0.0000 \\
\hline Gasoline, combusted in equipment & 0.0000 & 0.0000 & 0.0000 \\
\hline Diesel, combusted in equipment & 0.0002 & 0.0003 & 0.0003 \\
\hline Electricity & 0.0000 & 0.0002 & 0.0000 \\
\hline Total water footprint & 0.5944 & 0.6424 & 0.0893 \\
\hline $\begin{array}{l}\text { SD by Monte Carlo } \\
\text { ( } 95 \% \text { confidence })\end{array}$ & 0.0029 & 0.0023 & 0.0022 \\
\hline
\end{tabular}


Irrigation in the field production phase of the blue spruce model system was applied manually at each tree during dry periods. The other production systems used a traveling irrigation gun once annually, on average. Therefore, water applied to the blue spruce tree was $12 \%$ of the average for the other two trees. The WF of the liner production contributed less than $0.3 \%$ to the tree WF as a result of the high density of propagules per field area. Input materials and processes, excluding irrigation, contributed only $5.4 \%, 3.7 \%$, and $0.2 \%$ of the WF for the red maple, redbud, and blue spruce, respectively. For comparison, the redbud WF was lower using the Pfister $\left(0.356 \mathrm{~m}^{3}\right)$ and Boulay $\left(0.137 \mathrm{~m}^{3}\right)$ methods, which use different WSIs based on different models for global water availability and consumption.

\section{Conclusion}

This study provides midpoint environmental impact potentials for field production of trees including ozone depletion, smog, acidification, eutrophication, carcinogenic and non-carcinogenic human toxicity, respiratory effects, ecotoxicity, and fossil fuel depletion. These impact potentials, calculated for trees, compare favorably with several of the major commodities in production agriculture today. The other major contribution of this study was the inclusion of WF methods in the LCA analyses for trees. These procedures confirmed ex ante expectations that the field stage of tree production represents a much greater WF than the propagation stage, especially when using a per-plant comparison. The final contribution of this study centered on the approach to calculating environmental impacts. It was determined that using SimaPro and its embedded databases yielded comparable GWP for tree production system components to previously published, GWP-focused LCA studies using single-impact focused data from the literature that was compiled and calculated in a spreadsheet. This validated the use of SimaPro for estimating midpoint environmental impacts in green industry production systems.

\section{Literature Cited}

Alcamo, J., T. Henrichs, and T. Rosch. 2000. World water in 2025: Global modeling and scenario analysis for the World Commission on Water for the 21 st Century. Kassel World Water Ser. Rpt. No. 2.

Bare, J. 2011. TRACI 2.0: The tool for the reduction and assessment of chemical and other environmental impacts 2.0. Clean Technol. Environ. Policy 13:687-696.

Bare, J.C., G.A. Norris, D.W. Pennington, and T. McKone. 2003. TRACI-The tool for the reduction and assessment of chemical and other environmental impacts. J. Ind. Ecol. 6:49-78.

Boulay, A.-M., C. Bulle, J.-B. Bayart, L. Deschenes, and M. Margni. 2011. Regional characterization of freshwater use in LCA: Modeling direct impacts on human health. Environ. Sci. Technol. 45:8948-8957.

British Standards Institute. 2011. PAS 2050:2011: Specification for the assessment of the life cycle greenhouse gas emissions of goods and services. British Standards Institute, London, UK.

Cambria, D. and D. Pierangeli. 2011. A life cycle assessment case study for walnut tree (Juglans regia L.) seedlings production. Intl. J. Life Cycle Assessment 16:859-868.

Ecoinvent Centre. 2014. Ecoinvent 3.0. Competence Centre of the Swiss Federal Institute of Technology, Zurich, Switzerland. 17 Nov. 2014. <http://www.ecoinvent.org/database/>.

Fekete, B.M., C.J. Vörösmarty, and W. Grabs. 2002. High-resolution fields of global runoff combining observed river discharge and simulated water balances. Global Biogeochem. Cycles 16:1042.

Gleick, P.H., L. Allen, J. Christian-Smith, M.J. Cohen, H. Cooley, M. Heberger, J. Morrison, M. Palaniappan, and P. Schulte. 2011. The world's water. Vol. 7. Island Press, Washington, DC.
Hall, C.R. and D.L. Ingram. 2014. Production costs of field-grown Cercis canadensis L. 'Forest Pansy' identified during life cycle assessment analysis. HortScience 49:1-6.

Hoekstra, A.Y., M.M. Mekonnen, A.K. Chapagain, R.E. Mathews, and B.D. Richter. 2012. Global monthly water scarcity: Blue water footprints versus blue water availability. PLoS ONE 7:e32688.

Ingram, D.L. 2012. Life cycle assessment of a field-grown red maple tree to estimate its carbon footprint components. Intl. J. Life Cycle Assessment 17:453-462.

Ingram, D.L. 2013. Life cycle assessment to study the carbon footprint of system components for Colorado blue spruce field production and landscape use. J. Amer. Soc. Hort. Sci. 138:3-11.

Ingram, D.L. and C.R. Hall. 2013. Carbon footprint and related production costs of system components of a field-grown Cercis canadensis L. 'Forest Pansy' using life cycle assessment. J. Environ. Hort. 31:169-176. International Organization for Standardization. 2006. Life cycle assessment, requirements and guidelines. ISO Rule 14044:2006. ISO, Geneva, Switzerland.

McPherson, E.G. and J.R. Simpson. 1999. Carbon dioxide reduction through urban forestry guidelines for professional and volunteer tree planters. U.S. Dept. Agr., For. Ser. Pacific Southwest Res. Sta., Gen. Tech. Rpt. 171.

Mekonnen, M.M. and A.Y. Hoekstra. 2010a. A global and highresolution assessment of the green, blue and grey water footprint of wheat. Hydrol. Earth Syst. Sci. 14:1259-1276.

Mekonnen, M.M. and A.Y. Hoekstra. 2010b. The green, blue and grey water footprint of crops and derived crop products. Hydrol. Earth Syst. Sci. 15:1577-1600.

Müller-Wenk, R. 1998. Depletion of abiotic resources weighted on base of 'virtual' impacts of lower grade deposits used in future. IWÖ Diskussionsbeitrag No. 57. Institut für Wirtschaft und Ökologie, Universität St.Gallen, St. Gallen, Switzerland.

Muñoz, P., A. Antón, M. Nuñez, A. Paranjpe, J. Ariño, X. Castells, J.I. Montero, and J. Rieradevall. 2007. Comparing the environmental impacts of greenhouse versus open-field tomato production in the Mediterranean Region. Acta Hort. 801:1591-1596.

Nowak, D.J., D.E. Crane, J.C. Stevens, R.E. Hoehn, J.T. Walton, and J. Bond. 2008. A ground-based method of assessing urban forest structure and ecosystem services. Arboricult. Urban For. 34:347-358.

Peper, P.J., E.G. McPherson, J.R. Simpson, K.E. Vargas, and Q. Xiao. 2009. Lower midwest community tree guide: Benefits, costs and strategic planning. U.S. Dept. Agr., For. Ser. Pacific Southwest Res. Sta., Gen. Tech. Rpt. 219.

Perry, C. 2007. Efficient irrigation; inefficient communication; flawed recommendations. J. Irr. Drainage 56:367-378.

Pfister, S., A. Koehler, and S. Hellweg. 2009. Assessing the environmental impacts of freshwater consumption in LCA. Environ. Sci. Technol. 43:4098-4104.

Shiklomanov, I.A. 2000. Appraisal and assessment of world water resources. Water Intl. 25:11-32.

Smakthin, V., C. Revenga, and P. Doll. 2004. Taking into account environmental water requirements in global-scale water resources assessments. Comprehensive Assessment Water Res. Rpt. 2. Intl. Water Management Inst., Battaramulla, Sri Lanka.

Snyder, C.S., T.W. Bruulsema, T.L. Jensen, and P.E. Fixen. 2009. Review of greenhouse gas emissions from crop production systems and fertilizer management effect. Agr. Ecosyst. Environ. 133:247-266.

U.S. Department of Energy. 2014. U.S. life-cycle inventory database. 19 Aug. 2014. <https://www.lcacommons.gov/nrel/search>.

U.S. Environmental Protection Agency. 2008. Tool for the reduction and assessment of chemical and other environmental impacts (TRACI). 11 Sept. 2014. <http://www.epa.gov/ordntrnt/ORD/NRMRL/std/traci/ traci.html>.

USEtox. 2013. The USEtox model. 17 Nov. 2014. <http://www. usetox.org>.

Vyas, A. and M. Singh. 2011. GREET1_2011 (greenhouse gases, related emissions, and energy use in transportation). 19 Aug. 2014. <http:// www.transportation.anl.gov/modeling_simulation/VISION/>. 